\title{
Prólogo: um precipício no tempo
}

\author{
George W. Stocking Jr. \\ tradução: Íris Morais Araújo e Rafaela de Andrade Deiab \\ revisão técnica: LILIA MORITZ SCHWARCZ
}

Na Wessex de Thomas Hardy', o ano 1851 pareceu ao homem maduro "uma extraordinária fronteira cronológica" - "um precipício no Tempo". De repente, antigo e moderno foram trazidos "em contato absoluto", como em uma falha geológica. A disjuntura temporal era dramaticamente mais evidente há milhas de distância, em Londres, ponto de origem da ferrovia que havia recentemente alcançado a Stickleford ${ }^{2}$ de Hardy. Lá, em uma catedral de vidro dedicada ao Deus Progresso, cujos transeptos e nave estavam preenchidos com ícones da Revolução Industrial, era celebrada a primeira de todas "feiras mundiais": a Grande Exposiçáo dos Produtos da Indústria de Todas as Naçôes. Para os celebrantes de mentes mais filosóficas, como o Reverendo Dr. William Whewell, Master do Trinity College, Cambridge, vagar pelos corredores e galerias do "Palácio de Cristal" provocava a especulação sobre seu profundo "significado, poder e espírito". De modo pouco surpreendente, o simbolismo do Palácio estava em muitas bocas (Hardy, 1894, p.152; Whewell, 1852, p.6)3.

Uma gloriosa estufa de 1800 pés de comprimento e altura suficiente para encobrir um grupo de grandes olmos do Hyde Park; a própria construção espelhava os "triunfos das artes úteis sobre a natureza externa". Suas vigas de ferro fundido, colunas e os caixilhos mutuamente intercambiáveis foram um resultado colhido das oficinas de máquinas da Revoluçấo Industrial; seu exterior reluzente era um tributo ao livre comércio, que havia recentemente encorajado a remoção de um imposto sobre o vidro. Sua concepção e organização eram também um triunfo do espírito liberal empreendedor. Derivada de uma tradição de meio século de exposiçóes industriais francesas, a
Grande Exposição ganhou o seu caráter especial quando Henry Cole, um planejador-chefe ${ }^{4}$, notou que a França tinha rejeitado uma proposta de tornar internacional sua exposição de 1849 . Munido de visões de "Paz, Abundância e Prosperidade" em um mundo em que "a agressividade industrial, com o tempo, substituiria a agressão militar", Cole levou tal sugestão ao Príncipe Albert, ${ }^{5}$ que, como Presidente da Real Sociedade de Artes, ajudou a começar os planos para uma exposição britânica. O Príncipe Consorte respondeu favoravelmente: desde a manufatura e ciência até o bom gosto pertencentes "como um todo ao mundo civilizado, [e] a vantagem particular da Indústria britânica deveria ser derivada de se colocá-la em justa competição com as de outras naçôes". Na boa moda liberal, todo projeto foi levado adiante "sem que um shilling saísse do tesouro nacional", e a Comissão Real que supervisionava a construção teve, de fato, um belo lucro (Mayhew, 1851, p.155; Prince Albert apud Ffrench, 1950, p.22; Mayhew, 1851, p.137).

A Exposiçáo, que aconteceu somente poucos anos depois que Engels havia relatado a desesperada Condição da classe trabalhadora na Inglaterra, e que Disraeli ${ }^{6}$ havia visto o país dividido em "duas naçôes” entre as quais não havia nem diálogo, tampouco compaixão, teve grande importância simbólica e política. Embora o chartismo ${ }^{7}$ estivesse em decadência, e a Inglaterra escapasse ilesa dos eventos revolucionários que traumatizaram a Europa em 1848, as ondas de choque eram ainda fortes o suficiente para macular a Exposição. Rumores no Continente falavam de Londres fervilhando com Red Republicans inclinados ao assassinato, e foi apenas depois de algum debate que as

cadernos de campo, São Paulo, n. 19, p. 1-384, 2010 
292 | George W. Stocking JR.

cerimônias de inauguração foram abertas para o público geral. Punch $^{8}$ sentiu que elas eram uma "lição magnífica” para os príncipes prussianos - "um exemplo esplêndido daquela liberdade real [...] e perfeita seguridade [...] que são o resultado de nossa monarquia constitucional". A preocupação que as classes baixas, vindas posteriormente em um dia de semana com ingresso promocional, poderiam talhar suas iniciais nas vitrines, provaram-se igualmente infundadas; embora o rugido de prazer de 93 mil delas, com a aparição do Duque de Wellington ${ }^{9}$ em 7 de outubro, tenha causado um grande alarme; que o colapso de toda estrutura, há muito temido por alguns, teria finalmente começado (Engels, 1958; Disraeli, 1845, v.I, p.149; Punch apud Ffrench, 1950, p.193).

O próprio tamanho das multidóes simbolizou processos que rapidamente transformavam a sociedade tradicional britânica. O boom das ferrovias nos anos 1840 alcançou as províncias com 6.500 milhas de trilhos, e os camponeses, que tinham até então vivido em um mundo andarilho, eram agora despachados a 50 milhas por hora, em excursóes baratas de trem, para a metrópole. Imagens das ruas de Manchester e povoados de Cumberland vazios foram matéria de humor jornalístico, e é estimado que pelo menos um quinto da população britânica compareceu à Exposição durante seus seis meses (Mayhew; Cruikshank, 1851, p.17 e 54; Fay, 1951, p.73).

Mas como Dr. Whewell sugeriu, o simbolismo crucial do "Palácio de Cristal" se assentava sobre os objetos materiais confrontados por essa audiência massiva. De acordo com o sistema classificatório desenvolvido pelo químico Lyon Playfair, as grandes categorias exibidas - matérias-primas, maquinário, manufaturas e belas-artes - foram cada uma subdivididas, de modo que qualquer pessoa poderia localizar "máquinas de secar, máquinas de lavar, etc." como Subdivisão 19, Divisão C, Classe XXII (ferro e equipamento geral). Num excesso do espírito de livre comércio, Príncipe Albert propôs o agrupamento sem a referência à origem nacional; entretanto, a organização efetiva foi nacional e geográfica, uma vez que cada naçáo, na medida do praticável, organizou seus produtos de acordo com o sistema geral (Official Catalogue, 1851, v.I, p.104).

Ainda que a Rainha Pomare ${ }^{10}$ houvesse enviado esteiras pandanus ${ }^{11}$ do Taiti e o Rei de Daomé ${ }^{12}$ tenha contribuído com um trono de chefe, os princípios inflexíveis e autocentrados dos organizadores dificultaram a participação dos "aborígenes menos avançados". Contribuiçôes das colônias britânicas e dependências foram, em sua maioria, na categoria Matéria-Prima. Contudo, a grande exibição organizada pela Companhia do Leste da Índia incluiu itens em todas as trinta classes - a mais dramática, um grande e gordo elefante, com figuras humanas acomodadas em um assento de marfim posto no lombo do animal, dado à Rainha Vitória pelos Nazim de Moorshedabad ${ }^{13}$. Talvez desdenhoso de todo o esforço, o Império chinês requisitou somente 300 dos 5.000 pés quadrados que lhe haviam sido destinados; os Estados Unidos, pelo contrário, requisitaram espaço extra para uma mostra que incluía grandes atraçóes como o ceifeiro McCormick ${ }^{14}$ e bugigangas como caixões e caixas de frutas de "ar-exaustado", oferecidas por um nova-iorquino para preservar ambos, cadáver e comestíveis, da putrefação. De acordo com o Official Catalogue, as maiores contribuiçôes de fora da Grã-Bretanha vieram dos Estados Germânicos (em que o "artesanato" foi enfatizado ao invés da indústria pesada) e da França (cuja indústria bem desenvolvida era devotada mais aos objetos de luxo "da arte em miniatura" do que daqueles "de caráter mais ordinário e de demanda extensiva”) (Official Catalogue, 1851, v.III, p.1169).

Convenientemente, a expressão mais completa do espírito europeu da indústria civilizada foi encontrada na ala oeste. Lá, em salas repletas de maquinários em movimento, qualquer um poderia assistir aos poderosos teares mecânicos, aos modelos de locomotivas, às bombas centrífugas, às máquinas a vapor horizontais e verticais - "um 
Prólogo: UM PRECIPÍCIO NO TEMPO | 293

milhar de monstros de ferro bufando e fazendo estrondos". Visitantes estrangeiros foram seduzidos, e fazendeiros ingleses, empoeirados pela distância da qual vinham, permaneceram boquiabertos diante da Revolução Industrial britânica, pandemoníaca pelo seu barulho, mas livre de dor até o momento, rodando e empurrando diante de seus próprios olhos. Foi aqui que a moral da Exposição expressou-se de modo mais agudo (Mayhew; Cruikshank, 1851, p.134, 137).

Nas palavras do Príncipe Albert, a Exposição estava balizada nos grandes princípios complementares de "a unidade do gênero humano" e "a divisão do trabalho", através dos quais a humanidade se aproximava do cumprimento de sua "grande e sagrada missáo": o uso da razáo dada por Deus para descobrir as leis pelas quais o Onipotente regrou a criação; então pelas suas aplicaçóes o homem poderia "conquistar a Natureza para seu uso". A proposta da Exposição era "fornecer uma prova verdadeira e um quadro vivo do ponto no qual toda a humanidade chegou nesta grande tarefa, e um novo ponto de partida de onde todas as nações estarão aptas a direcionar seus esforços futuros" (apud Official Catalogue, 1851, v.I, p 3-4).

A lição mais óbvia da Exposição, contudo, foi que, ao perseguir sua missão sagrada, nem todos os homens haviam avançado no mesmo passo, ou chegado ao mesmo ponto. Refletindo sobre este fato, Dr. Whewell afirmou a unidade do homem como artesáo e artista; até mesmo o mais rude dos selvagens compartilhava uma capacidade humana genérica para a invenção. Não havia "realmente nada bárbaro na habilidade e no gosto" dos trabalhos ornamentais do Oriente. O que distinguia as civilizaçóes "estacionárias" do Leste das "progressivas" do Oeste, e sobretudo a Grã-Bretanha, era um princípio social. Aqui, "a máquina com seus milhões de dedos trabalha para milhôes de consumidores, enquanto nos países remotos, onde magnificência e selvageria caminham lado a lado, dezenas de milhares trabalhavam para um". Homens com visões menos otimistas da ordem social britânica falavam a mesma mensagem em diferentes tons. Henry Mayhew ${ }^{15}$, mesmo trabalhando na documentação dos horrores do "trabalho degradado" e dos "cortiços" de Londres, viu a Exposição como "uma enorme academia para ensinar a nobreza do labor", e para provar que os "pobres industriosos ao invés do rico indolente" eram "os homens realmente respeitáveis deste país”. Mas não era por acaso que o labor britânico havia feito o Palácio de Cristal; "nenhum outro povo no mundo poderia ter erguido tal prédio": "uma olhada de relance era completamente suficiente para dar-se conta da grandiosidade da nação à qual o Palácio de Cristal pertencia!" (Whewell, 1852, p.16-19; Mayhel; Cruikshank, 1851, p.137, 155-156; Yeo; Thompson, 1971).

Apesar das esperanças de seus mais exuberantes patrocinadores, a Grande Exposição não inaugurou uma era de competição industrial amigável e de paz internacional; tampouco sinalizou a transformaçáo de trabalhadores de fábricas em "artistas de nossas manufaturas", como Mayhew previu. Apesar disso, o Palácio de Cristal parece, em retrospecto, haver marcado a abertura da "era de equilíbrio" dos meados da Era Vitoriana; uma harmonia temporária entre as poderosas e algumas vezes conflitantes forças remodeladoras da sociedade britânica. A descoberta de ouro na Austrália e Califórnia marcou o começo de um boom econômico sem precedentes que durou até 1873 . Prosperidade agrícola, rápido crescimento da produção industrial, preços e lucros crescentes, maiores rendas em muitos segmentos da sociedade, incluindo porçōes da classe trabalhadora; tudo isso contribuiu para o decréscimo da tensão política e para uma relativa tranquilidade social numa sociedade que, para aqueles que compartilhavam de seus benefícios, parecia um modelo para o mundo emular. Como Lord Palmerston ${ }^{16}$ sugeriu: "Nós mostramos o exemplo de uma nação, em que cada classe da sociedade aceita com alegria o quinháo que a Providência lhe destinou; enquanto isso, ao mesmo tempo, todo indivíduo de cada classe está 
294 | George W. Stocking JR.

constantemente lutando para subir na escala social - não pela injustiça e pecado, não pela violência e ilegalidade, mas pela preservação de boa conduta e execução constante e energética das faculdades morais e intelectuais com as quais seu Criador thes havia dotado. (Mayhew; Cruikshank, 1851, p.129; Palmerston apud Briggs, 1953, p.404; Burn, 1965; Stocking Jr., 1987, cap.6).

Nem todo mundo na Grã-Bretanha beneficiou-se como no exemplo de Palmerston. De fato, a harmonia da era de equilíbrio alicerçava-se pesadamente sobre a pobreza urbana, as classes trabalhadoras não organizadas, os rendeiros e os trabalhadores rurais. Por baixo da superfície plácida da sociedade de meados da era vitoriana havia "abismos temíveis de fanatismo e selvageria". Se os maiores problemas da ordem social pareciam resolvidos, homens "respeitáveis" "por nenhum momento assumiram que a naçáo estava segura em uma plataforma de caminho divino: suas insistências sobre a necessidade de honestidade, castidade, temperança e frugalidade eram ditadas pelas ameaças de desonestidade, sensualidade, embriaguez e improvidência”. Quando a Era Vitoriana começou, "o velho, severo e selvagem mundo do século XVIII estava então desaparecendo". Qualquer pessoa "que tivesse mais de trinta anos em 1850, tinha vivido em um mundo em que não só não havia estradas de ferro, mas tampouco polícia para se recorrer". Estas pessoas de meia-idade, no momento do Palácio de Cristal, não só teriam visto "grandes mudanças", mas também teriam sido "usadas como um exemplo trivial para muito daquilo que nós consideraríamos muito brutal e primitivo". (Burn, 1965, p.332, 341; Clark, 1962, p.62, 60).

Estamos de volta, então, ao "precipício no Tempo" de Hardy. A ordem social urbana e industrial simbolizada pelo Palácio de Cristal era um fenômeno muito recente em 1851, uma transformação no tempo da vida dos homens que o construíram, uma transformaçấo ainda não consumada por muitos dos quais o testemunharam - e também para milhões na Grã-Bretanha que não o fizeram. Não só essa transformação criou novos cancros de sofrimento e selvageria urbana, mas também deixou muitas áreas rurais pouco tocadas. Até muito tarde no progresso da industrialização, "a estrutura social do campo inglês mudou muito pouco em relação ao que era esperado". "A Inglaterra tradicional" não foi tão transformada, mas gradualmente diminuída em relação à "Inglaterra industrial", até que foi "finalmente reduzida a uma franja insignificante" (Laslett, 1965, p.xiii). Neste contexto, a sensaçâo de disjunção temporal poderia ser, de fato, realmente aguda, e muitos daqueles que testemunharam a Exposição - seja como a soma de sua própria experiência, seja como uma sombra antecipada de um mundo ainda por ser experimentado - devem ter se sentido parados em um precipício no tempo.

Era pouco surpreendente, entáo, que a Exposição forçasse alguns a pensar sobre as origens e o progresso da civilizaçáo que ela resumia. Muito no Palácio de Cristal encorajava à especulação sobre um aspecto mais específico: o sistema geral de classificação, que forçou os jurados a comparar o mesmo objeto funcional em uma variedade de formas nacionais; o caráter das diferentes exposiçóes nacionais, que os levou ao longo de uma linha de progresso que parte da Tasmânia selvagem, passando pelas civilizaçóes "bárbaras" do Leste, e cruzando em sentido noroeste o continente europeu até o seu ápice, na Grá-Bretanha; mesmo as colheres de cobre fundido de Joseph Tylor and Sons, foram dispostas de modo a demonstrar "as mudanças em seus padróes" e em suas "diferentes melhorias desde 1780 até o tempo presente". Ainda que os futuros interesses evolucionistas do filho de 19 anos de Tylor, Edward, não pareçam ter qualquer débito direto com a Exposição, isso só pode ser matéria de especulaçãa. Mas há evidências para sugerir que as duas grandes coleçôes etnológicas do período evolucionista - a Christy e a Pitt Rivers - foram estimuladas pela Grande Exposição. Henry Christy (o banqueiro londrino que era, casualmente, companheiro de Tylor em sua viagem ao México em 1856) começou seus estudos sobre hábitos e cos- 
tumes primitivos como resultado de sua visita ao Palácio de Cristal. General Pitt Rivers - então ainda Capitão Lane Fox das Guardas Grenadianas ${ }^{17}$ - começou sua coleção mais ou menos ao mesmo tempo, e seu princípio especial de classificação por forma (com lanças, arcos, clavas etc. cada qual agrupados em séries que iam do simples ao complexo) sustenta uma semelhança óbvia com aquele empregado no julgamento na Exposição (Official Catalogue, 1851, v.II, p.642; Christy, 1862; Exhibition, 1965; Chapman, 1985; Pitt Rivers, 1906).

Em sua contribuição para uma série de palestras sobre os resultados da Exposição, Dr. Whewell especulava sobre a relação entre espaço e tempo. Diferentes naçóes haviam alcançado diferentes estágios no progresso das "artes úteis e ornamentais", e todos esses estágios poderiam ser vistos de uma só vez "em um vidro mágico que os feiticeiros do nosso tempo tinham feito brotar do chão como uma emanação". Lá, "a infância, a juventude, a idade adulta e a maturidade das naçōes", todas elas apareciam "em seus aspectos simultâneos, como os objetos mais distantes revelados, no mesmo momento, por um flash de luz em uma noite sombria". Portanto, "pela aniquilaçáo do espaço, que separa diferentes naçóes, nós produzimos um espetáculo no qual é também aniquilado o tempo que separa um estágio de progresso de uma nação de outro" (Whewell, 1852, p.13-14).

Whewell náo é uma figura associada ao "evolucionismo". Seu ponto de vista filosófico geral era antitético àquele incorporado à tradição evolucionista britânica; e embora mais tarde ele admitisse sentir o peso do argumento de Darwin, não permitiria a Origem [das Espécies] nas prateleiras da biblioteca do Trinity College. Tudo isso talvez torne ainda mais significativo que sua consideração sobre "O Postulado Geral da Grande Exposiçấo no Progresso da Arte e da Ciência”, deveria tê-lo levado a formular o princípio básico do evolucionismo sociocultural: o "método comparativo" (Himmelfarb, 1959, p.287; Cannon, 1964, p.176-191; Stocking Jr., 1987, cap.1, p.37-38).

Os trabalhos clássicos do evolucionismo so- ciocultural britânico foram todos produtos da era de equilíbrio. Se alguém fosse encapsular em uma frase sua definiçáo contextual mais geral, não poderia fazer mais do que descrever esses trabalhos como uma tentativa de entender a experiência cultural simbolizada pelo Palácio de Cristal.

\section{Notas}

1. N.T.: Thomas Hardy (1840-1928) foi um poeta e romancista inglês famoso pelas descriçōes do país imaginário chamado Wessex (lugar primeira vez descrito em Far from the madding crowd, 1874). Nascido no extremo sul da Inglaterra, Hardy idealizava a vida rural deste país.

2. N.T.: Stickleford é a cidade imaginária de Hardy.

3. Sobre a Grande Exposição, ver, entre outros, Beaver, 1970; Briggs, 1953; Ffrench, 1950; Gibbs-Smith, 1950; Tallis, 1852).

4. N.T.: Henry Cole foi, posteriormente, diretor do British Museum of London.

5. N.T.: O Príncipe Albert foi o marido da Rainha Vitória.

6. N.T.: Disraeli (1804-1881) é autor de três romances em defesa da população pobre. Ator político do Partido Conservador, na Câmara dos Comuns também foi defensor de uma política assistencialista para a camada desfavorecida da época.

7. N.T.: O chartismo foi um movimento de reforma política e social estabelecido pelos trabalhadores ingleses entre os anos 1830 e 1850.

8. Punch foi revista inglesa de sátira do século XIX.

9. N.T.: O Duque de Wellington (1769-1852) foi soldado, embaixador, líder do exército inglês e, após o biênio entre 1828 e 1830, quando foi Primeiro Ministro, passou a acumular cargos de confiança da Rainha Vitória no governo inglês.

10. N.T.: Pomare era a rainha do Taiti.

11. N.T.: O pandanu é uma espécie de fibra encontrada no Taiti.

12. N.T.: O Daomé era uma regiáo africana localizada entre os atuais Benin e Nigéria.

13. N.T.: Moorshedabad era uma regiáo, à época, pertencente da Colônia Britânica na Índia.

14. N.T.: O ceifeiro McCormick era uma máquina de colheita agrícola.

15. N.T.: Henry Mayhew foi um jornalista da revista Punch.

16. N.T.: Lord Palmerston foi um nobre e pensador da Era Vitoriana.

17. N.T.: As Guardas Grenadianas são um dos mais antigos regimentos do exército britânico. 
296 | George W. Stocking JR.

\section{Referências bibliográficas}

BEAVER, Patrick. The Crystal Palace, 1851-1936. London: Hugh Evelyn, 1970.

BRIGGS, Asa. The Crystal Palace and the men of 1851. In: Victorian people. New York, 1953.

BURN, W. L. The age of equipoise. New York: Norton, 1965.

CANNON, Walter. William Whewell, F. R. S. (17941866) II: contributions to science and learning. Notes and records: Royal Society of London, London, v. 19, n. 2, p. 176-191, 1964.

CHAPMAN, W. R. Arranging ethnology: A. H. L. F. Pitt Rivers and the typological tradition. In: Stocking Jr., G. W. (Org.). Objects and others. Esays on museums and material culture. Madison: University of Wiscosin Press, 1985. p. 15-48.

CHRISTY, Henry. Catalogue of a collection of ancient and modern stone implements and other weapons, tools and utensils of the aborigenes of various countries. London, 1862.

CLARK, G. K. The making of Victorian England. London: Methuen, 1962.

DISRAELI, Benjamin. Sybil, of, the two nations. London: Colburn, 1845 (3 v.).

ENGELS, Friedrich. The condition of the working class in England. California: Stanford University Press, [1845] 1958.

FAY, C. R. Palace of industry, 1851. Cambridge: Cambridge University Press, 1951.

FRENCH, Yvonne. The Great Exhibition, 1851. London: Harvill Press, 1950.

GIBBS-SMITH, Charles Havard. The Great Exhibition of 1851. London: HMSO, 1950.
HARDY, Thomas. The fiddler of the reels. In: Lifés little ironies. London, 1894.

HIMMELFARB, Gertrude. Darwin and the Darwinian revolution. Garden City: Doubleday, 1959.

LASLETT, Peter. The world we have lost. London: Methuen, 1965.

MAYHEW, Henry; CRUICKSHANK, George. 1851. Or, the adventures of Mr. And Mrs. Sandboys and family who came up to London to enjoy themselves, and to see the great exhibition. London: D. Bogue, 1851.

PITT-RIVERS. Principles of classification. In: The evolution of culture and other essays. Oxford: Clarendon Press, [1874] 1906. p. 1-19.

STOCKING JR., George W. Philanthropoids and vanishing cultures: Rockefeller fundind and the and of the museum era in Anglo-American anthropology. In: (ed.). Objects and others. Essays on museu$\mathrm{ms}$ and material culture. Madison, University of Wiscosin Press, 1985. p. 112-146.

Victorian Anthropology. New York: Free Press, 1987

TALLIS, John. Tallis's history and description of the Crystal Palace, and the exhibition of the world's industry in 1851. London: J. Tallis and co., 1852.

WHEWELL, William. The general bearing of the Great Exhibition of the progress of art and science. In: Lectures on the results of the Great Exhibition of 1851 delivered before the Society of Arts, Manufactures, and Commerce. London: G. Barclay, 1852. p. 3-34.

YEO, Eileen; THOMPSON, E. P. The unknown Mayhew. New York: Pantheon Books, 1971.

\title{
traduzido de
}

STOCKING Jr., George W. Prologue: A Precipice in Time. In:

Victorian Anthropology. New York: Free Press, 1987, p.1-6.

\author{
tradutora Íris Morais Araújo \\ Doutoranda em Antropologia Social / USP
}

tradutora Rafaela de Andrade Deiab

Mestre em Antropologia Social / USP

revisora Lilia Moritz Schwarcz

Professora Titular de Antropologia / USP

Doutora em Antropologia Social / USP

Recebida em 05/10/2010

Aceita para publicação em 05/10/2010

cadernos de campo, São Paulo, n. 19, p. 291-296, 2010 